\title{
Molecular signaling pathways underlying schizophrenia
}

\section{Tiihonen, Jari}

2021-06

Tiihonen , J , Koskuvi , M , Lähteenvuo , M , Trontti , K , Ojansuu , I, Vaurio , O , Cannon , D T, Lönnqvist, J , Therman , S , Suvisaari , J , Cheng , L, Tanskanen, A, Taipale , H , Lehtonen , S \& Koistinaho , J 2021, ' Molecular signaling pathways underlying schizophrenia ', Schizophrenia Research , vol. 232 , pp. 33-41 . https://doi.org/10.1016/j.schres.2021.05.011

http://hdl.handle.net/10138/333921

https://doi.org/10.1016/j.schres.2021.05.011

cc_by

publishedVersion

Downloaded from Helda, University of Helsinki institutional repository.

This is an electronic reprint of the original article.

This reprint may differ from the original in pagination and typographic detail.

Please cite the original version. 


\title{
Molecular signaling pathways underlying schizophrenia
}

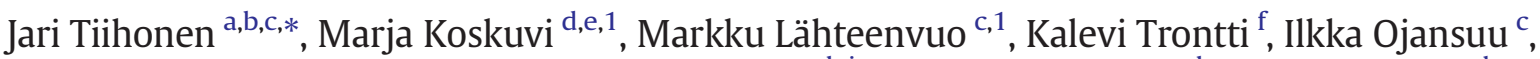 \\ Olli Vaurio ${ }^{\mathrm{c}}$, Tyrone D. Cannon ${ }^{\mathrm{g}}$, Jouko Lönnqvist h,i, Sebastian Therman ${ }^{\mathrm{h}}$, Jaana Suvisaari ${ }^{\mathrm{h}}$, \\ Lesley Cheng ${ }^{\mathrm{j}}$, Antti Tanskanen ${ }^{\mathrm{a}, \mathrm{c}}$, Heidi Taipale ${ }^{\mathrm{a}, \mathrm{c}, \mathrm{k}}$, Šárka Lehtonen ${ }^{\mathrm{d}, \mathrm{e}}$, Jari Koistinaho ${ }^{\mathrm{d}, \mathrm{e}}$ \\ a Department of Clinical Neuroscience, Karolinska Institutet, Stockholm, Sweden \\ b Center for Psychiatry Research, Stockholm City Council, Stockholm, Sweden \\ c Department of Forensic Psychiatry, University of Eastern Finland, Niuvanniemi Hospital, Kuopio, Finland \\ d A.I. Virtanen Institute for Molecular Sciences, University of Eastern Finland, Kuopio, Finland \\ e Neuroscience Center, University of Helsinki, Helsinki, Finland \\ f SleepWell Research Program and Department of Psychology and Logopedics, Faculty of Medicine, University of Helsinki, Helsinki, Finland \\ ${ }^{g}$ Department of Psychology and Psychiatry, Yale University, New Haven, CT, USA \\ ${ }^{\mathrm{h}}$ Mental Health Unit, Department of Public Health Solutions, National Institute for Health and Welfare, Helsinki, Finland \\ ${ }^{i}$ Department of Psychiatry, University of Helsinki, Helsinki, Finland \\ j Department of Biochemistry and Genetics, La Trobe Institute for Molecular Science, La Trobe University, Bundoora, VIC, Australia \\ k School of Pharmacy, University of Eastern Finland, Kuopio, Finland
}

\section{A R T I C L E I N F O}

\section{Article history:}

Received 20 November 2020

Received in revised form 16 April 2021

Accepted 2 May 2021

Available online 16 May 2021

\section{Keywords:}

Schizophrenia

Stem cell

hiPSc

Pathway

\begin{abstract}
A B S T R A C T
The molecular pathophysiological mechanisms underlying schizophrenia have remained unknown, and no treatment exists for primary prevention. We used Ingenuity Pathway Analysis to analyze canonical and causal pathways in two different datasets, including patients from Finland and USA. The most significant findings in canonical pathway analysis were observed for glutamate receptor signaling, hepatic fibrosis, and glycoprotein 6 (GP6) pathways in the Finnish dataset, and GP6 and hepatic fibrosis pathways in the US dataset. In data-driven causal pathways, ADCYAP1, ADAMTS, and CACNA genes were involved in the majority of the top 10 pathways differentiating patients and controls in both Finnish and US datasets. Results from a Finnish nation-wide database showed that the risk of schizophrenia relapse was $41 \%$ lower among first-episode patients during the use of losartan, the master regulator of an ADCYAP1, ADAMTS, and CACNA-related pathway, compared to those time periods when the same individual did not use the drug. The results from the two independent datasets suggest that the GP6 signaling pathway, and the ADCYAP1, ADAMTS, and CACNA-related purine, oxidative stress, and glutamatergic signaling pathways are among primary pathophysiological alterations in schizophrenia among patients with European ancestry. While no reproducible dopaminergic alterations were observed, the results imply that agents such as losartan, and ADCYAP1/PACAP -deficit alleviators, such as metabotropic glutamate 2/3 agonist MGS0028 and 5-HT7 antagonists - which have shown beneficial effects in an experimental Adcyap $1^{-1}$ mouse model for schizophrenia could be potential treatments even before the full manifestation of illness involving dopaminergic abnormalities.

(C) 2021 The Authors. Published by Elsevier B.V. This is an open access article under the CC BY license (http:// creativecommons.org/licenses/by/4.0/).
\end{abstract}

\section{Introduction}

The first effective pharmacological treatments for schizophrenia were discovered more than 60 years ago, and ever since, all of them have been full or partial dopamine $\mathrm{D}_{2}$-receptor antagonists. Therefore, on the basis of the dopamine hypothesis, it was believed for decades that the main pathophysiology underlying the clinical phenotype was a defect in the dopaminergic system (McCutcheon et al., 2020).

\footnotetext{
* Corresponding author at: Department of Clinical Neuroscience, Karolinska Institutet, Norra Stationsgatan 69, Plan 7, SE-171 77 Stockholm, Sweden.

E-mail address: jari.tiihonen@ki.se (J. Tiihonen).

1 Equal contribution.
}

However, only a minority of patients reach full recovery or remission when treated with medications currently available, and, especially, negative and cognitive symptoms are commonly resistant to existing antipsychotic treatments (McCutcheon et al., 2020). There is increasing evidence that, in addition to dopaminergic defects, also abnormal glutamatergic, GABAergic, and serotoninergic signaling, as well as inflammation and oxidative stress contribute to the pathophysiology of schizophrenia (McCutcheon et al., 2020; Yang and Tsai, 2017).

Although large-scale genetic studies have been able to reveal hundreds of gene polymorphisms associated with schizophrenia (Schizophrenia Working Group of the Psychiatric Genomics Consortium, 2014), the attributable fraction of each gene is only a few per mille at best, and the findings have not been able to elucidate how 
these variants contribute to complex molecular pathways in abnormal brain development leading to mental illness. The same applies to postmortem studies (Breen et al., 2019; Gandal et al., 2018; Girdhar et al., 2018) since postmortem brain tissue is affected by treatment and course of the illness. However, the pathophysiology of neurological and psychiatric disorders can be modeled using human induced pluripotent stem cell (hiPSC)-derived neurons. So far, these studies (Brennand et al., 2011; Tiihonen et al., 2019) have tried to identify abnormalities related to illness by analyzing how differentially expressed genes (DEGs) interact in established pathways such as GO and KEGG, based on previous literature on gene functions, but no reproducible results identifying novel potential treatments have been published using these analyses. Ingenuity Pathway Analysis (IPA) is a data-driven method that may increase the possibilities to detect disease-specific abnormalities (Krämer et al., 2014). This type of analysis was used in a recent study, showing that nFGR1 signaling is a potential common dysregulated mechanism in schizophrenia (Narla et al., 2017). Now we used IPA in two independent hiPSC-neuron datasets as well as a national pharmacoepidemiological database in order to find potential novel treatments based on molecular pathways underlying schizophrenia, and to study whether any of these findings are consistent and reproducible.

\section{Methods}

The methods were performed in accordance with relevant guidelines and regulations and approved by the Ethics Committee of the Helsinki University Hospital District (license number 262/EO/06). All participants provided written informed consent to take part in the study, and gave consent to publish results which do not allow identification of the participants (such as age, sex, and RNA levels). No identifying information of the participants is included.

Each subject was diagnosed and assessed by a trained psychiatrist according to the Diagnostic and Statistical Manual of Mental Disorders, fourth edition criteria based on a structured clinical interview (see the details in Tiihonen et al., 2019; Hoffman et al., 2017).

\subsection{Pathway analysis}

We applied knowledge-based Ingenuity Pathway Analysis (Krämer et al., 2014) to investigate two published DEG datasets comparing hiPSC-derived neurons from patients with schizophrenia to those of unrelated healthy individuals (Hoffman et al., 2017; Tiihonen et al., 2019). In addition, we aimed to include a comparison of monozygotic twin pairs discordant for schizophrenia, but this comparison yielded only one DEG surviving correction for multiple comparisons (Tiihonen et al., 2019), and no pathway analysis was possible. In order to have a larger number of DEGs for pathway analysis, we made a new comparison with neuronal cells dissociated for final maturation from neuroprogenitors maintained in culture for 12 weeks, including the same five twin pairs as earlier (in the previous studies, hiPSC-derived neuronal cells were maintained in culture for 6 (Hoffman et al., 2017) and 10 (Tiihonen et al., 2019) weeks). In total, these datasets included results from 37 individuals ( 16 patients, 16 healthy unrelated controls, and 5 unaffected monozygotic twins). All 15 individuals included in the Finnish dataset were Caucasian and of Finnish origin. In the US dataset, 9 of 11 patients were Caucasian and 2 Caucasian-Hispanic, and 5 of 11 controls were Caucasian, the rest 6 having mixed ethnicity (Supplementary data 1, Hoffman et al., 2017). The gene expression was studied initially in 19,462 genes in the Finnish dataset (see Tiihonen et al., 2019) and 39,815 genes in the US dataset (see Hoffman et al., 2017). From all three datasets, genes with a minimum of 2-fold change in expression and adjusted $\mathrm{p}<0.05$ (232 DEGs/231 genes mapped by IPA (Tiihonen et al., 2019) for affected twin vs. controls, and 356 DEGs/352 mapped by IPA for unaffected twin vs. controls; new hiPSC-derived neuron data made for this work, 69 DEGs/all mapped by IPA) or nominal $\mathrm{p}<0.05$ (108 DEGs/100 mapped by IPA, Hoffman et al., 2017) were used as input for IPA core analysis, and run with default settings against data content version 49932394 (dated 2019-11-15). In causal pathway analysis, the software used previous knowledge on molecular pathways to identify a master regulator, which regulated a cluster of genes via several upstream regulators. The methodological details of canonical and causal pathways analyses are described in Krämer et al. (2014).

DEG lists applied to IPA, and the newly produced RNA-sequencing data are stored in University of Helsinki data cloud (https://datacloud. helsinki.fi), accessible via the link: https://datacloud.helsinki.fi/index. php/s/MjdMNcW2QMt7zFk.

Hoffman et al. (2017) SZ vs control DEG data of neurons was downloaded from https://www.nature.com/articles/s41467-01702330-5\#Sec35 (Supplementary data 8).

Note to reviewers: The above RNA-sequencing data are available in Gene Expression Onmibus via link GSE174704, https://www.ncbi.nlm. nih.gov/geo/query/acc.cgi?acc=GSE174704.

\section{2. hiPSC cell culture work}

\subsection{1. hiPSC methods of previously published datasets}

Details on hiPSC methods of datasets comparing patients with schizophrenia versus healthy controls are reported on pages 8-9 in Tiihonen et al., 2019, and on pages 11-12 in Hoffman et al., 2017; see the links in Supplementary material.

\subsection{2. hiPSC cell culture and neural differentiation in monozygotic twins}

Methods of cell culturing, RNA sequencing, and DEG analysis followed those published previously (Tiihonen et al., 2019, see the link in Supplementary material). Briefly, hiPSCs cultured in E8 medium (Thermo Fisher Scientific) on Matrigel-coated dishes were differentiated to neurons using dual SMAD inhibitors SB431542 and LDN193189 (Selleckchem) for 10 days. The neuroprogenitor cells formed the spheres and were maintained in floating culture for 12 weeks instead of 10, as previously published (Tiihonen et al., 2019). The cells were dissociated with Accutase for the final maturation in monolayer culture for one week before RNA collection.

\subsubsection{RNA isolation and transcriptomic analysis of monozygotic twins}

RNA was isolated from the plated neurons by RNeasy mini kit (Qiagen) according to the manufacturer's protocol. The Agilent 2100 Bioanalyzer confirmed the required quality of RNA before the whole transcriptome sequencing was performed on the Illumina Hiseq 2500 by the Sequencing laboratory of Institute for Molecular Medicine Finland FIMM Technology Centre, University of Helsinki. The sequencing data normalization and DEG analysis were performed using R package DESeq2, v. 1.16.1, as previously.

\subsection{Pharmacoepidemiological analysis}

We studied the risk of hospitalization due to psychosis (as indicator for severe relapse) in a Finnish nationwide cohort of patients with schizophrenia during use of angiotensin II receptor antagonists versus no use of the drug within the same individuals (to eliminate selection bias). The role of general treatment adherence was studied by investigating the risk of hospitalization during use of thiazide diuretics, used for the same somatic indication (hypertension). The details of the method are shown in Supplementary methods and Supplementary Tables 1,2 , and 3 .

\subsection{Data availability}

All data needed to evaluate the conclusions in the manuscript are provided in the manuscript or the Supplementary material. 


\section{Results}

\subsection{Pathway analysis}

Table 1a shows the top 10 canonical pathways in the Finnish dataset (Tiihonen et al., 2019) comparing patients and unrelated healthy controls, and all pathways are shown in Supplementary Table 4. The most significant pathways were glutamate receptor signaling and white adipose tissue browning pathway ( $\mathrm{p}=1.3 \times 10^{-4}$ in both), the first involving glutamate ionotropic receptor kainate type subunit 2 (GRIK2), glutamate receptor ionotropic NMDA2B-subunit (GRIN2), metabotropic glutamate receptor 1 (GRM1), vesicular glutamate transporter 1 (SLC17A6), and vesicular glutamate transporter 2 (SCL17A7) genes. The combined effect of these altered gene expressions in the glutamate signaling pathway leads to increased postsynaptic neurotoxicity, synaptic plasticity, excitatory potentials, and receptor, as shown in Fig. 1a. In the comparison between affected vs. unaffected twins in the novel Finnish dataset (prepared for this study), the most statistically significant canonical pathways were hepatic fibrosis/hepatic stellate cell activation $\left(\mathrm{p}=7.9 \times 10^{-20}\right)$, and glycoprotein 6 (GP6) signaling $\left(\mathrm{p}=1.3 \times 10^{-12}\right.$ ) pathways (Table $1 \mathrm{~b}$, Supplementary Table 5, Fig. 1b). In the US dataset (Hoffman et al., 2017), the most significant finding was observed for glycoprotein 6 (GP6, p = 3.0 $\left.\times 10^{-6}\right)$ and hepatic fibrosis/hepatic stellate cell activation $\left(\mathrm{p}=3.8 \times 10^{-5}\right)$ pathways, including many same genes (Table 1c, Supplementary Table 6, Fig. 1c).

Table 2 shows the results for the top 10 data-driven pathways, highlighting schizophrenia-related genes, and all pathways and genes are illustrated in Supplementary Table 4 (Finnish dataset) and Supplementary Table 6 (US dataset). Both datasets included a large number of genes linked previously with schizophrenia (see Supplementary Table 7). In the Finnish dataset, the most significant pathways were regulated by P2RY11 purine receptor and losartan potassium (angiotensin II receptor antagonist used as a treatment for hypertension), both including several genes coding glutamate receptors and transporters (Supplementary Figs. 1 and 2). In the US dataset, the strongest findings were observed for pathways regulated by cytosolic phospholipase Cpla2 and the alpha-adrenergic receptor (Supplementary Figs. 3 and 4). Also astaxanthin-regulated pathway, including CACNA1A gene was observed in the US dataset (Table 2). ADCYAP1, ADAMTS, and CACNA genes were included in most of the top 10 pathways in both Finnish and US datasets. Still, dopamine-related genes (DRD2 and COMT) were observed only in the Finnish dataset, and GABA-related genes (GABRA2) only in the US dataset (Table 2, Fig. 2). Collagen genes were included in numerous pathways in both datasets, implying abnormal cell adhesion and extracellular matrix in schizophrenia (Su et al., 2017). Fig. 2 illustrates the genes related to purine receptor, oxidative stress, and glutamate receptor signaling.

\section{a Glutamate receptor signaling pathway (the Finnish dataset)}

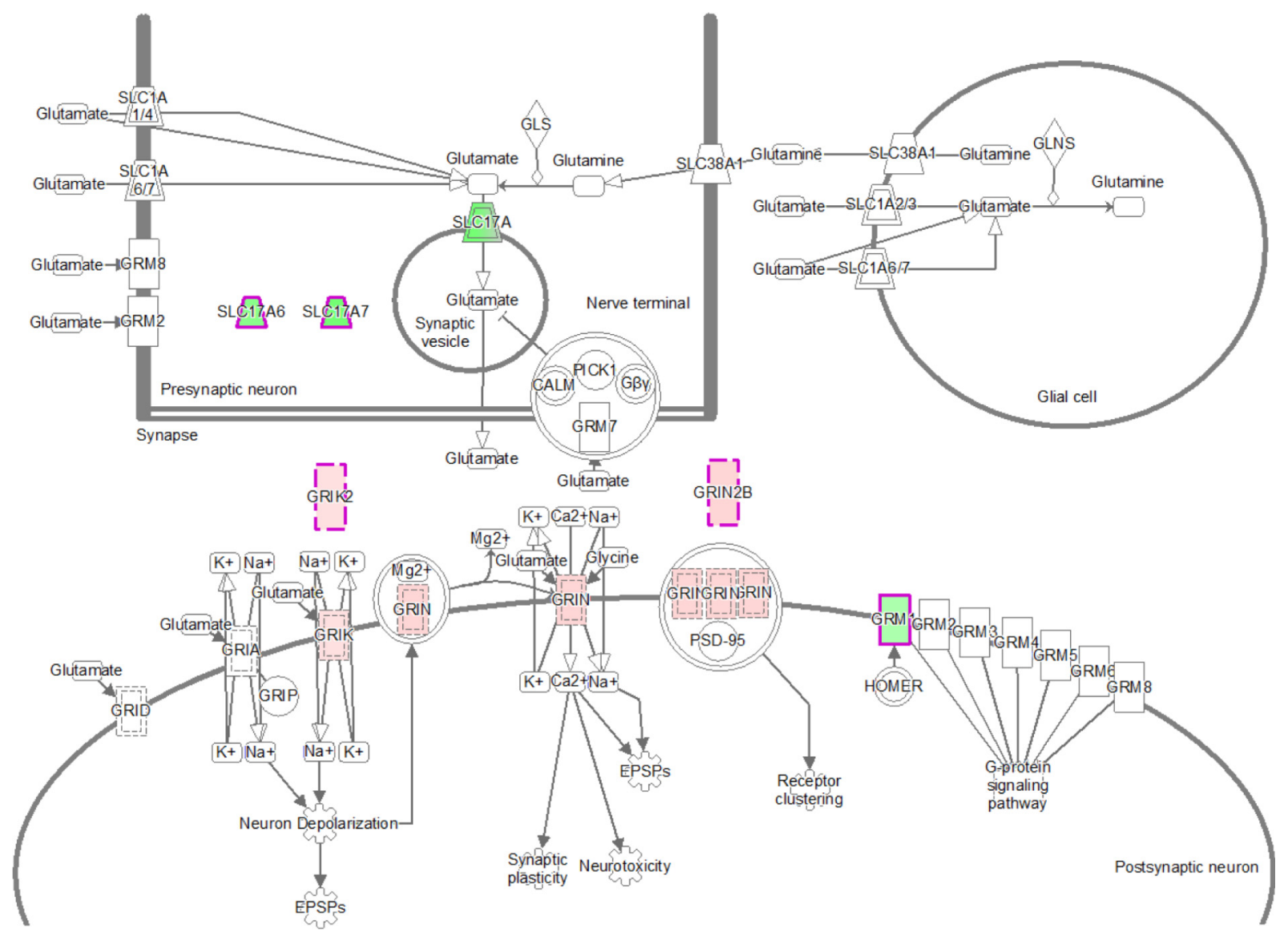

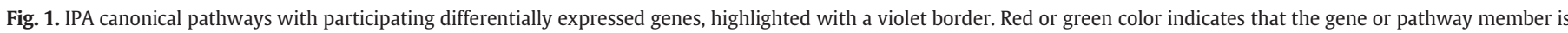

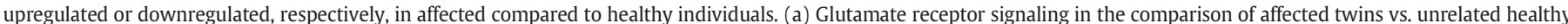

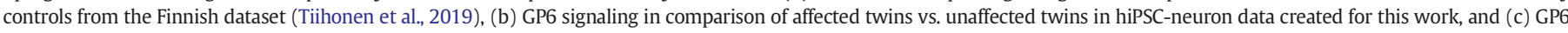
signaling from the US dataset (Hoffman et al., 2017) showing the comparison of patients with schizophrenia vs. healthy individuals. 


\section{b GP6 signaling pathway (the Finnish dataset)}

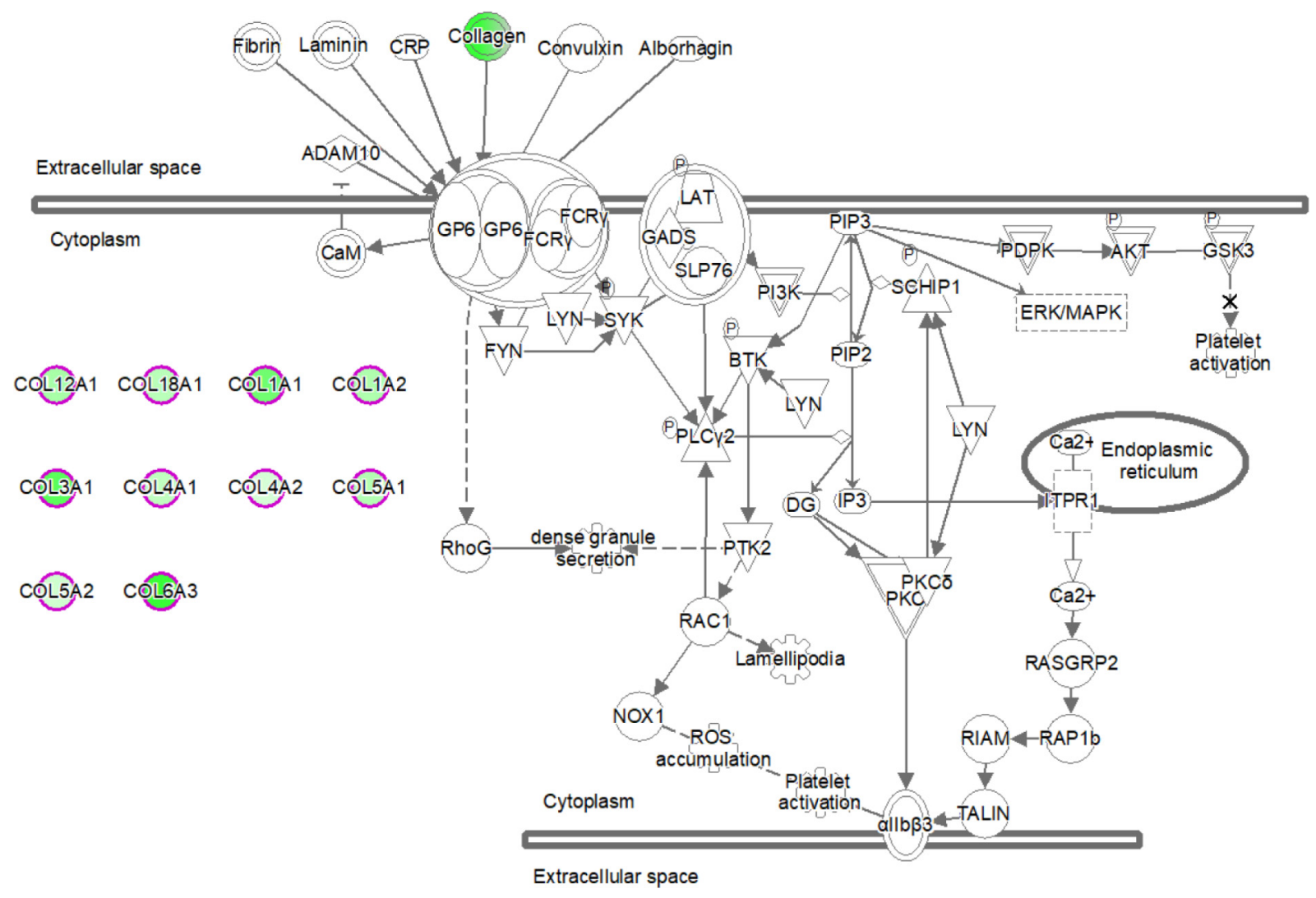

Fig. 1 (continued).

In the comparison between Finnish affected vs. unaffected twins, the most significant pathway was complement $\mathrm{C} 3 / 4$ receptor-like 1 (CR1L) regulated pathway ( $\mathrm{p}=2.6 \times 10^{-18}$, Supplementary Table 5, Supplementary Fig. 5). There was considerable overlap of regulated genes in CR1L-regulated pathway and GP6 and hepatic fibrosis pathways since the majority of GP6 and CR1L genes were included in hepatic fibrosis/ hepatic stellate cell activation pathway. Most of those common genes coded for collagen. As can be seen in Tables 1b and 1c, the most significant findings were seen for the same canonical pathways (GP6 and hepatic fibrosis/hepatic stellate cell activation) in the comparison between patients vs. controls in the US dataset, and in the comparison between affected vs. unaffected twins in the Finnish dataset.

Supplementary Table 8 shows canonical and causal pathways for comparison between unaffected twins versus healthy controls. As expected, the effect sizes were smaller than in the comparison between affected twins versus healthy controls. In the canonical pathway analysis, the comparison between affected versus unaffected twins showed the strongest finding for hepatic fibrosis and GP 6 pathways, whereas in the comparison between affected twins versus unrelated healthy controls, the most significant finding was glutamatergic signaling pathway. This is apparently explained by the fact that unaffected twins share partially the same abnormalities as their affected twins - for example, GRIN2B was upregulated and CACNA2D downregulated among them when compared with healthy controls. Therefore, the glutamatergic pathway does not show up in the comparison between affected versus unaffected twins. This suggests that glutamatergic abnormalities are associated with the shared familiar risk among affected and unaffected twins, and GP 6 pathway is associated with the actual clinical illness.

\subsection{Pharmacoepidemologic analyses}

Fig. 3 shows the risk of rehospitalizations due to psychosis (indicator for severe relapse) in a Finnish nationwide cohort of patients with schizophrenia. Use of any angiotensin II receptor antagonist was associated with $27 \%$ lower risk, and use of losartan with $27 \%$ (95\% CI 20\%-34\%) lower risk of rehospitalization due to psychosis compared with those time periods in the total cohort when the same individual was not using the drug (within-individual analysis). In the incident cohort of 8342 first-episode patients with a median age of 36 years, the corresponding decrease for losartan use was $41 \%$ ( $95 \%$ CI 14\%-60\%). The results for thiazide diuretics, used for the same somatic indication (hypertension), indicated that the findings were not attributable to general adherence to drug treatments. Antipsychotic use was associated with only slightly lower (46\% vs. $41 \%$ ) risk of rehospitalization than losartan use among the incident cohort, but no beneficial outcome was observed for benzodiazepine use. The raw data are shown in Supplementary Tables 9a and 9b.

\section{Discussion}

To our knowledge, this is the first study to analyze schizophreniaspecific molecular pathways from two independent datasets, showing a consistent overlap of altered gene expression. While glutamate receptor signaling was highly abnormal only among Finnish patients compared with unrelated healthy controls in the canonical pathway analysis, GP 6 and hepatic fibrosis/hepatic stellate cell activation were the most significant pathways in the comparison between patients and healthy controls 


\section{c GP6 signaling pathway (the US dataset)}

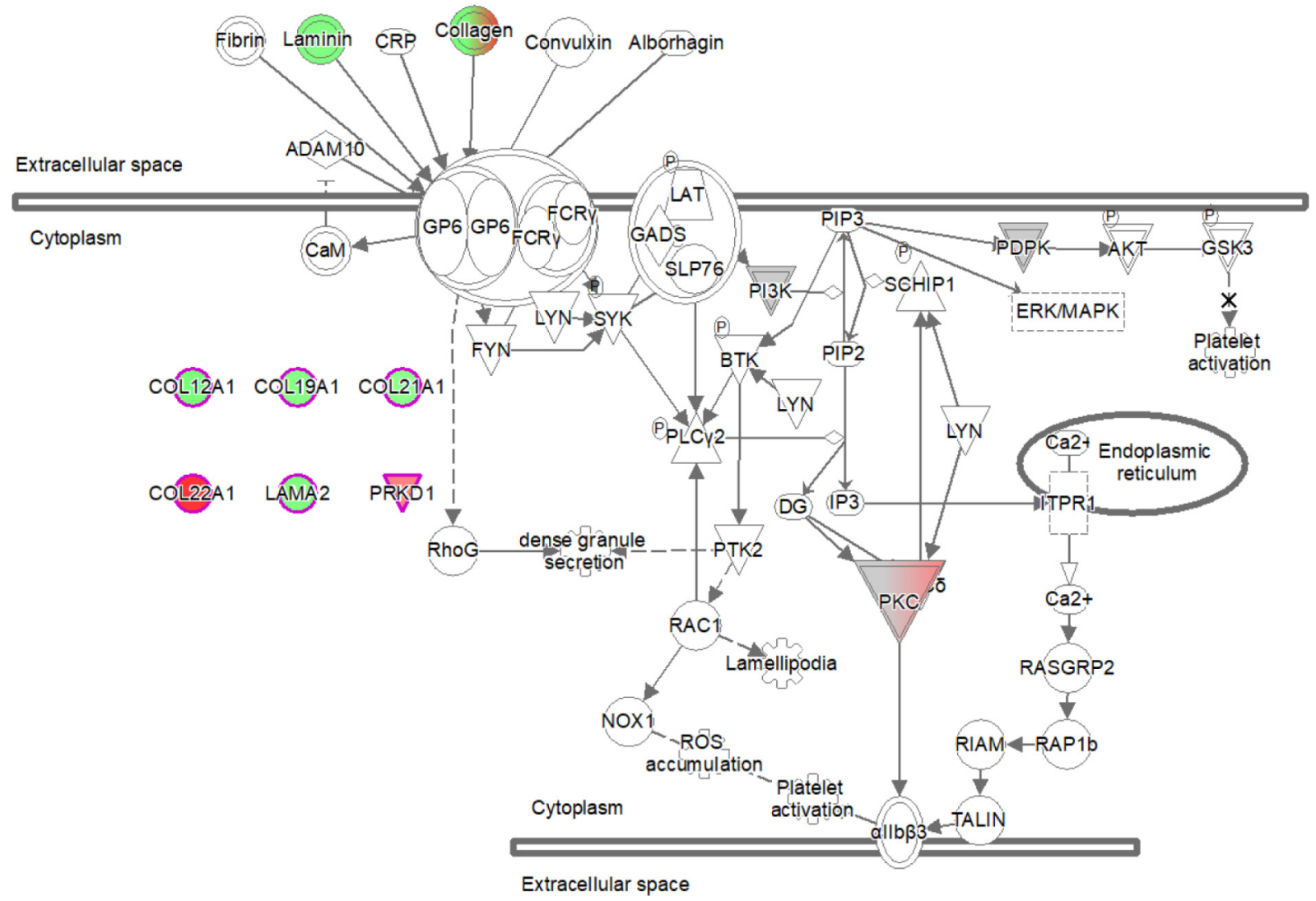

Fig. 1 (continued)

in the US dataset, and in the comparison between affected and unaffected monozygotic twins in the Finnish dataset. The finding on GP 6 pathway is in line with a large body of literature showing abnormalities in extracellular matrix (ECM) and perineuronal nets (PNNs) in schizophrenia (Berretta, 2012; Wen et al., 2018). A recent study (Narla et al., 2017) using the US dataset found that hepatic fibrosis/hepatic stellate cell activation was the most significant signaling pathway in IPA analysis, and ECM organization the most significant signaling pathway in Reactome analysis, but these findings were not highlighted because the study focused on FGFR1. ECM regulates cell migration, differentiation, neuronal plasticity, and neurite outgrowth, and a disintegrin and matrix metalloproteases with thrombospondin motif (ADAMTS) cleave ECM molecules for dynamic functional adaptations (Chelini et al., 2018). PNNs are assemblies of extracellular glycoproteins which ensheath parvalbumin-expressing
GABA interneurons, and they protect neurons from oxidative stress (Wen et al., 2018). ADCYAP1, ADAMTS, and CACNA were involved in the majority of the statistically most significant causal pathways in both Finnish and US datasets. Although both dopaminergic and GABAergic genes were expressed in both datasets, dopamine-related genes (DRD2, COMT) contributed to the most significant pathways only in the Finnish dataset, and GABAergic gene (GABRA2) only in the US dataset.

In the comparison between patients with schizophrenia and healthy controls, the number 1 canonical pathway in the Finnish dataset (glutamate receptor signaling, Table $1 \mathrm{a}$ ) included 5 DEGs, 2 of which (GRIN2B and GRM1) belong to the same gene families coding for NMDA (GRIN2A) and metabotropic glutamate (GRM3) receptors identified in GWAS (Pardiñas et al., 2018). In the US dataset, the number 1 canonical pathway (GP6 signaling pathway, Table 1c) PRKD1 was one of the 6 DEGs
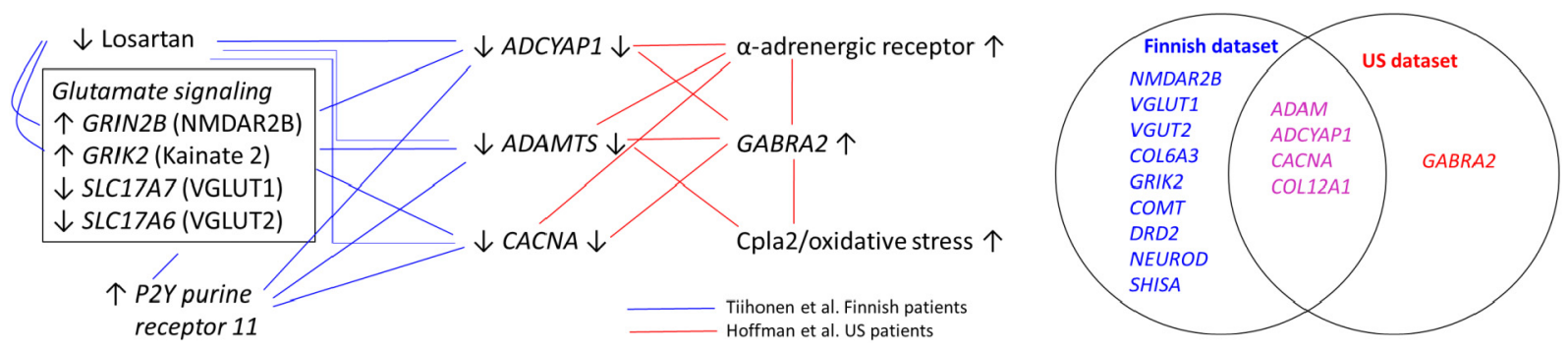

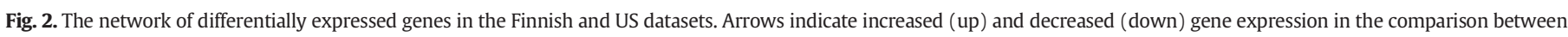

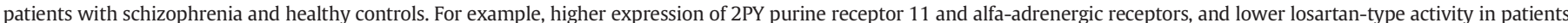

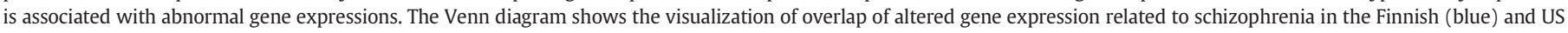
(red) datasets. Common genes for both datasets are indicated by violet color. 
Table 1a

The top 10 canonical pathways observed in the comparison between patients with schizophrenia and healthy unrelated controls in the Finnish dataset.

\begin{tabular}{|c|c|c|c|}
\hline Ingenuity canonical pathways & p-Value & Z score & Molecules \\
\hline Glutamate receptor signaling & $1.3 \mathrm{E}-04$ & & GRIK2, GRIN2B, GRM1, SLC17A6, SLC17A7 \\
\hline White adipose tissue browning pathway & $1.3 \mathrm{E}-04$ & -1.1 & CACNA2D1, CACNG5, FNDC5, NPPA, PPARGC1A, PRDM16, PRKG2 \\
\hline Cellular effects of sildenafil (viagra) & $1.4 \mathrm{E}-04$ & & CACNG5, GPR37, KCNQ3, NPPA, PDE1A, PRKG2, SLC4A10 \\
\hline Dermatan sulfate biosynthesis & $1.5 \mathrm{E}-04$ & -1.3 & B3GAT1, DSEL, HS3ST1, NDST3, NDST4 \\
\hline Dermatan sulfate biosynthesis (late stages) & $6.5 \mathrm{E}-04$ & -1 & DSEL, HS3ST1, NDST3, NDST4 \\
\hline Thyroid cancer signaling & $9.6 \mathrm{E}-04$ & & CDH1, CXCL12, NTRK1, TCF7L2 \\
\hline Transcriptional regulatory network in embryonic stem cells & $1.2 \mathrm{E}-03$ & & EOMES, GBX2, SIX3, ZFHX3 \\
\hline Chondroitin sulfate biosynthesis & $1.4 \mathrm{E}-03$ & -2 & B3GAT1, HS3ST1, NDST3, NDST4 \\
\hline Neuropathic pain signaling in dorsal horn neurons & $1.8 \mathrm{E}-03$ & -0.4 & GPR37, GRIN2B, GRM1, KCNQ3, TAC1 \\
\hline Heparan sulfate biosynthesis & $4.6 \mathrm{E}-03$ & -2 & B3GAT1, HS3ST1, NDST3, NDST4 \\
\hline
\end{tabular}

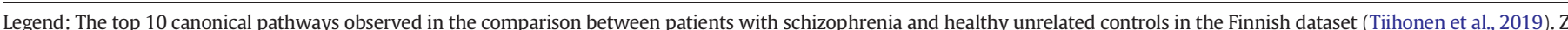
score cannot be calculated if the pathway has less than 4 genes, or sufficient information for the gene effects is not available to estimate the magnitude of the overall effect.

contributing to the pathway, and it is also associated with schizophrenia in GWAS (Pardiñas et al., 2018). ADAMTS, ADCYAP1, and CACNA were common (shared) genes/gene families in the Finnish and US dataset (Table 2). Of these, ADAMTS and CACNA genes are associated with schizophrenia in GWAS (Pardiñas et al., 2018). It should be noted that several homeostatic regulatory mechanisms tend to normalize gene expression and protein synthesis even when the gene itself is not initially optimally functional.

The strongest genetic association with schizophrenia has been localized in the major histocompatibility complex (MHC) locus (Schizophrenia Working Group of the Psychiatric Genomics Consortium, 2014), and later it was shown that this association is partially attributable to diverse alleles of the complement component (C4) genes (Sekar et al., 2016). A recent study demonstrated that $C 4$ variants are associated with inflammation and excessive synaptic pruning mediated by monocytes differentiated to microglia direction in the iPSC-derived neurons of patients with schizophrenia (Sellgren et al., 2019). In our analyses, several pathways differentiating patients from controls included pathways related to inflammation and oxidative stress. In the comparison between Finnish monozygotic twins discordant for schizophrenia, the most significant major regulator was complement $\mathrm{C} 3 \mathrm{~b} / 4 \mathrm{~b}$ receptor 1-like gene (CR1L). So far, CR1L has been linked to Alzheimer's disease (Zhu et al., 2015), but our results suggest that CR1L-regulated C4 activation may also have an important contribution to the development of schizophrenia. In the US dataset, cytosolic phospholipase 2 (Cpla2) was the master regulator for a causal pathway, including ADAMTS2 and GABRA2. Cpla2 is involved in inflammatory responses, and it is increased in schizophrenia and autism (Xu et al., 2019). The P2RY11-regulated pathway in the Finnish dataset and the astaxanthin-regulated pathway in the US dataset imply an abnormal purine-related molecular cascade underlying, which is in line with data from small RCTs suggesting beneficial effects for purinergic agents (Hirota and Kishi, 2013).
The results on the losartan-regulated causal pathway involving ADCYAP1, ADAMTS9, CACNA2D1, COMT, GRIK2, NMDAR2B, and VGLUT2 are in line with previous studies indicating that angiotensin II receptor antagonists may have a beneficial effect on mental disorders (Benicky et al., 2011; Fan et al., 2017; Oh and Fan, 2019). This implies that losartan and other angiotensin II receptor antagonists (ARBs) might be effective also in schizophrenia (Fan et al., 2017). Furthermore, our pharmacoepidemiological data showed that in the total nationwide cohort, the use of losartan and another widely used angiotensin II receptor antagonists was associated with about a $25 \%$ to $30 \%$ lower risk of hospitalization due to psychosis compared to those time periods when the same individual did not use an angiotensin II receptor antagonist. This beneficial association was even stronger in the younger first-episode cohort, showing a $41 \%$ lower risk of rehospitalization during the use of losartan. These findings were not explained by the overall temporal variation in treatment compliance since no effect was observed for thiazide diuretics used for the same indication, hypertension. Concerning specific ARBs, the outcome was not associated with the permeability through the blood-brain-barrier (BBB). Losartan's access through the BBB is considered rather poor in the healthy brain without trauma or neuropsychiatric illness. However, data from animal studies show that it can penetrate brain after oral administration. It inhibits epileptic seizures by preventing astrocyte activation (Hong et al., 2019), inhibiting albumin-induced PNN degradation around parvalbumin interneurons (Kim et al., 2017), and reducing BBB dysfunction (Swissa et al., 2019). It also enhances the extinction of fear memory when administered peripherally (Marvar et al., 2014). ARBs decrease brain inflammation and glutamate excitotoxicity via central and peripheral mechanisms and repurposing them for treatment of neuropsychiatric disorder may be of major immediate and translational value (Villapol and Saavedra, 2015). While losartan was associated with decreased risk of relapse in schizophrenia, especially among first-episode patients, hypothetically,

Table 1b

The top 10 canonical pathways in the comparison between affected and unaffected twins in the Finnish dataset.

\begin{tabular}{|c|c|c|c|}
\hline Ingenuity canonical pathways & p-Value & $\begin{array}{l}\text { Z } \\
\text { score }\end{array}$ & Genes \\
\hline Hepatic fibrosis/hepatic stellate cell activation & $7.9 \mathrm{E}-20$ & & $\begin{array}{l}\text { CCN2, COL12A1, COL18A1, COL1A1, COL1A2, COL3A1,COL4A1, COL4A2, COL5A1, COL5A2, COL6A3, FN1, } \\
\text { IGFBP3, IL1R1, MYH7, TGFBR2 }\end{array}$ \\
\hline GP6 signaling pathway & $1.3 \mathrm{E}-12$ & -3.2 & COL12A1, COL18A1, COL1A1, COL1A2, COL3A1, COL4A1, COL4A2, COL5A1, COL5A2, COL6A3 \\
\hline Apelin liver signaling pathway & $8.1 \mathrm{E}-07$ & -2 & COL18A1, COL1A1, COL1A2, COL3A1 \\
\hline Hepatic fibrosis signaling pathway & $8.7 \mathrm{E}-07$ & -3 & CCN2, COL18A1, COL1A1, COL1A2, COL3A1, IL1R1, MYLK, TGFBR2, WNT8B \\
\hline Intrinsic prothrombin activation pathway & $5.9 \mathrm{E}-06$ & -2 & COL18A1, COL1A1, COL1A2, COL3A1 \\
\hline Osteoarthritis pathway & $3.2 \mathrm{E}-04$ & -2 & DCN, FN1, IL1R1, TGFBR2, WNT8B \\
\hline Atherosclerosis signaling & $4.5 \mathrm{E}-04$ & & COL18A1, COL1A1, COL1A2, COL3A1 \\
\hline Dendritic cell maturation & $1.8 \mathrm{E}-03$ & -2 & COL18A1, COL1A1, COL1A2, COL3A1 \\
\hline $\begin{array}{l}\text { Role of osteoblasts, osteoclasts and chondrocytes in } \\
\text { rheumatoid arthritis }\end{array}$ & $3.5 \mathrm{E}-03$ & & COL1A1, DKK2, IL1R1, WNT8B \\
\hline Inhibition of angiogenesis by TSP1 & $4.2 \mathrm{E}-03$ & & TGFBR2, THBS1 \\
\hline
\end{tabular}

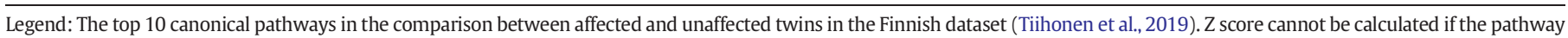
has less than 4 genes, or sufficient information for the gene effects is not available to estimate the magnitude of the overall effect. 
Table 1c

The top 10 canonical pathways observed in the comparison between patients with schizophrenia and healthy unrelated controls in the US dataset.

\begin{tabular}{|c|c|c|c|}
\hline Ingenuity canonical pathways & p-Value & Z score & Genes \\
\hline GP6 signaling pathway & $3.0 \mathrm{E}-06$ & -0.8 & COL12A1, COL19A1, COL21A1, COL22A1, LAMA2, PRKD1 \\
\hline Hepatic fibrosis/hepatic stellate cell activation & $3.8 \mathrm{E}-05$ & & COL12A1, COL19A1, COL21A1, COL22A1, LHX2, MYH14 \\
\hline Transcriptional regulatory network in embryonic stem cells & $1.4 \mathrm{E}-02$ & & NEUROG1, OTX1 \\
\hline Retinoic acid mediated apoptosis signaling & $1.7 \mathrm{E}-02$ & & CFLAR, RXRG \\
\hline Cardiac hypertrophy signaling (enhanced) & $2.3 \mathrm{E}-02$ & 1 & ADRA1A, CACNA1A, FZD8, MPPED2, PRKD1 \\
\hline ILK signaling & $2.6 \mathrm{E}-02$ & & DSP, FLNC, MYH14 \\
\hline Superoxide radicals degradation & $2.6 \mathrm{E}-02$ & & CAT \\
\hline Fc $\gamma$ RIIB signaling in B lymphocytes & $2.6 \mathrm{E}-02$ & & CACNA1A, INPP5D \\
\hline VDR/RXR activation & $2.8 \mathrm{E}-02$ & & $P R K D 1, R X R G$ \\
\hline IL-3 signaling & $2.9 \mathrm{E}-02$ & & INPP5D, PRKD1 \\
\hline
\end{tabular}

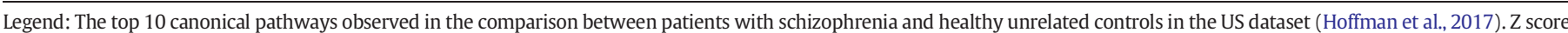
cannot be calculated if the pathway has less than 4 genes, or sufficient information for the gene effects is not available to estimate the magnitude of the overall effect.

its most beneficial effect should be seen in primary prevention if it could normalize the pathophysiological cascade related to down-regulated ADCYAP1, ADAMTS, and CACNA genes.

Although the number of participants was smaller in the Finnish dataset $(\mathrm{n}=15)$ than in the US dataset $(\mathrm{n}=22)$, the findings were substantially stronger in the Finnish dataset. This was probably due to the more homogeneous study population, resulting in less illnessirrelevant genetic noise. In our previous study, we observed that the number of sex-specific genes increased as a function of time during the maturation of cells (Tiihonen et al., 2019). Also, the analyses of the present study showed that the number of DEGs is higher when the neurons have matured for a longer time. Although the US dataset included several non-Caucasian controls, the results were surprisingly similar to those from the Finnish dataset. The most consistent finding across the Finnish and US datasets was the involvement of the ADCYAP1 gene in the majority of the most significant causal pathways. ADCYAP1 codes the pituitary adenylate cyclase-activating polypeptide (PACAP) protein, which upregulates DISC1 (disrupted in schizophrenia 1, Lutfy and Shankar, 2019). It also modulates dendritic spine maturation and morphogenesis (Hayata-Takano et al., 2019) and has been studied extensively in schizophrenia and other psychiatric disorders (Ago et al., 2013). One study has shown that metabotropic glutamate 2/3 agonist MGS0028 improves impairments in the novel object recognition test in mice lacking PACAP in an experimental Adcyap $1^{-1-}$ mouse model for schizophrenia (Ago et al., 2013). Another study showed that PACAP-deficient mice have psychomotor and cognitive deficits and that 5-HT7 antagonist SB269970 ameliorated these deficits (Tajiri et al., 2012). Our results indicate how gene expression is altered in fetal-like neurons in schizophrenia, and the expression of genes is probably quite different on the adult age after the onset of illness. Our analyses suggest that in the pathophysiological cascade of schizophrenia, abnormalities in the expression of genes associated with glutamatergic neurotransmission, neuron maturation, and extracellular matrix-related signaling pathways occur first, and dopaminergic abnormalities emerge later during prodromal phase and clinical illness. This suggests that MGS0028 and 5-HT7 antagonists could be potential treatments in primary prevention before the full manifestation of illness involving dopaminergic abnormalities. As discussed above, the DEG results obtained from hiPSC-derived neurons do not necessarily reflect the DEG results in the neurons of adult individuals of 20 to 30 years of age. This can be considered a limitation when considering how the results can be applied to treatment of full-blown illness. In any case, the results may provide important insight into the pathophysiological cascade preceding the onset of illness.

A major limitation of hiPSC-studies is the small number of subjects due to the laborious method. Our study included a total of 37 individuals which is a rather small sample but, to our knowledge, the largest to date in schizophrenia research using hiPSC-derived neurons. Despite the sample size, findings on ADCYAP1, ADAMTS, and CACNA-related signaling pathways were surprisingly consistent in two independent datasets. Since the pathway analyses comparing patients and healthy unrelated

Table 2

Top 10 upstream master regulators and their target genes in the Finnish and US datasets comparing patients and healthy unrelated controls

\begin{tabular}{|c|c|c|c|c|c|c|c|}
\hline \multicolumn{4}{|c|}{ Tiihonen et al. (2019) dataset } & \multicolumn{4}{|c|}{ Hoffman et al. (2017) dataset } \\
\hline $\begin{array}{l}\text { Master } \\
\text { regulator }\end{array}$ & $\begin{array}{l}\text { p-Value } \\
\text { of } \\
\text { overlap }\end{array}$ & $\begin{array}{l}\text { Network } \\
\text { bias-corrected } \\
\text { p-value }\end{array}$ & Target molecules in dataset & Master regulator & $\begin{array}{l}\text { p-Value } \\
\text { of } \\
\text { overlap }\end{array}$ & $\begin{array}{l}\text { Network } \\
\text { bias-corrected } \\
\text { p-value }\end{array}$ & $\begin{array}{l}\text { Target molecules in } \\
\text { dataset }\end{array}$ \\
\hline P2RY11 & $3.9 \mathrm{E}-10$ & 0.0001 & $\begin{array}{l}\text { ADAMTS9, ADCYAP1, CACNA2D1, COMT, GRIK2, GRIN2B, } \\
\text { NEUROD1, NEUROD6, SHISA6, SLC17A6, SLC17A7 }\end{array}$ & Cpla2 & $2.9 \mathrm{E}-08$ & 0.0003 & ADAMTS2, GABRA2 \\
\hline $\begin{array}{l}\text { Losartan } \\
\text { potassium }\end{array}$ & $8.6 \mathrm{E}-10$ & 0.0001 & $\begin{array}{l}\text { ADAMTS9, ADCYAP1, CACNA2D1, COMT, GRIK2, GRIN2B, } \\
\text { NEUROD1, NEUROD6, SLC17A6 }\end{array}$ & $\begin{array}{l}\text { Alpha-adrenergic } \\
\text { receptor }\end{array}$ & $5.7 \mathrm{E}-08$ & 0.0004 & $\begin{array}{l}\text { ADAMTS2, ADCYAP1, } \\
\text { CACNA1A }\end{array}$ \\
\hline TAF4 & $9.8 \mathrm{E}-10$ & 0.0001 & $\begin{array}{l}\text { ADCYAP1, CACNA2D1, COMT, DRD2, GRIK2, NEUROD1, } \\
\text { NEUROD6, SHISA6, SLC17A6 }\end{array}$ & GCKR & $8.8 \mathrm{E}-08$ & 0.0003 & $\begin{array}{l}\text { ADAMTS2, ADCYAP1, } \\
\text { CACNA1A }\end{array}$ \\
\hline PRKD2 & $1.6 \mathrm{E}-09$ & 0.0001 & $\begin{array}{l}\text { ADAMTS9, ADCYAP1, CACNA2D1, COMT, GRIK2, } \\
\text { NEUROD1, NEUROD6, SLC17A6 }\end{array}$ & Costunolide & $4.1 \mathrm{E}-07$ & 0.0017 & $\begin{array}{l}\text { ADAMTS2, ADCYAP1, } \\
\text { CACNA1A, GABRA2 }\end{array}$ \\
\hline AKT1S1 & $1.7 \mathrm{E}-09$ & 0.0001 & $\begin{array}{l}\text { ADAMTS9, ADCYAP1, CACNA2D1, COMT, NEUROD6, } \\
\text { SLC17A6, SLC17A7 }\end{array}$ & ICL1-9 & $6.7 \mathrm{E}-07$ & 0.0011 & $\begin{array}{l}\text { ADAMTS2, ADCYAP1, } \\
\text { CACNA1A }\end{array}$ \\
\hline CABIN1 & $2.8 \mathrm{E}-09$ & 0.0001 & $\begin{array}{l}\text { ADAMTS9, ADCYAP1, CACNA2D1, COMT, DRD2, GRIK2, } \\
\text { GRIN2B, NEUROD6, SLC17A6 }\end{array}$ & Fcgr3 & $8.9 E-07$ & 0.0013 & $\begin{array}{l}\text { ADAMTS2, ADCYAP1, } \\
\text { CACNA1A, GABRA2 }\end{array}$ \\
\hline CaMK I & $7.2 \mathrm{E}-09$ & 0.0002 & $\begin{array}{l}\text { ADAMTS9, ADCYAP1, CACNA2D1, COMT, DRD2, GRIK2, } \\
\text { GRIN2B, NEUROD1, NEUROD6, SLC17A6 }\end{array}$ & NCSTN & $1.1 \mathrm{E}-06$ & 0.0024 & $\begin{array}{l}\text { ADAMTS2, ADCYAP1, } \\
\text { CACNA1A }\end{array}$ \\
\hline $\begin{array}{l}\text { Retinoic } \\
\text { acid-RAR-RXR }\end{array}$ & $1.1 \mathrm{E}-08$ & 0.0001 & $\begin{array}{l}\text { ADAMTS9, CACNA2D1, COMT, DRD2, GRIK2, NEUROD1, } \\
\text { NEUROD6, SHISA6, SLC17A6 }\end{array}$ & L-tyrosine & $1.2 \mathrm{E}-06$ & 0.0007 & ADAMTS2, CACNA1A \\
\hline GEM & $1.2 \mathrm{E}-08$ & 0.0001 & CACNA2D1, GRIK2, NEUROD1, NEUROD6, SLC17A6 & Astaxanthin & $1.9 \mathrm{E}-06$ & 0.0007 & CACNA1A \\
\hline RP 73401 & $1.5 \mathrm{E}-08$ & 0.0004 & $\begin{array}{l}\text { ADAMTS9, ADCYAP1, CACNA2D1, COMT, GRIK2, GRIN2B, } \\
\text { NEUROD6, SLC17A6 }\end{array}$ & ADRB1 & $1.9 \mathrm{E}-06$ & 0.0009 & ADCYAP1, CACNA1A \\
\hline
\end{tabular}

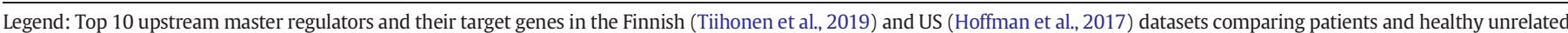
controls. Common (shared) genes/members of a gene family in both datasets are in bold. Common (shared) genes/members of a gene family in both datasets are in bold. 


\section{a) Prevalent cohort}

P-values were 0.0001 for any ARB, $<0.0001$ for candesartan, 0.1762 for eprosartan, $<0.0001$ for losartan $<0.0001$ for valsartan 0.4345 for telmisartan, 0.9614 for olmesartan, $<0.0001$ for antipsychotics, $<0.0001$ for benzodiazepines, and 0.1439 for thiazides. Cut-off value with Bonferroni correction is $p<0.0055$.

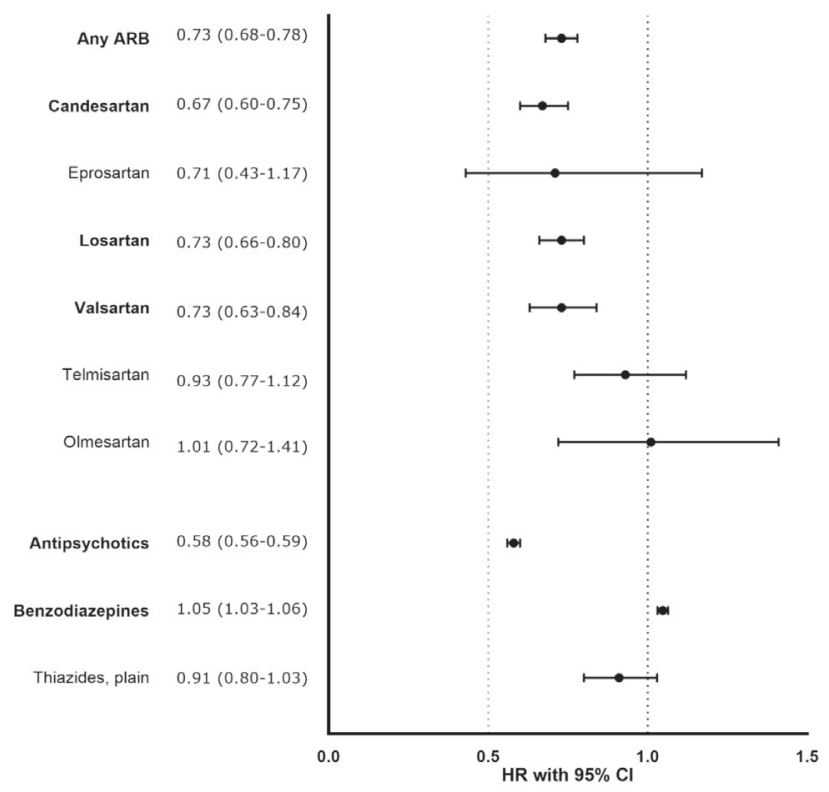

b) Incident cohort

P-values were 0.0486 for any ARB, 0.0065 for losartan, 0.5880 for valsartan, 0.8800 for candesartan, 0.4795 for telmisartan, $<0.0001$ for antipsychotics, 0.0002 for benzodiazepines, and 0.0121 for thiazides. Cut-off value with Bonferroni correction is $p<0.0071$.

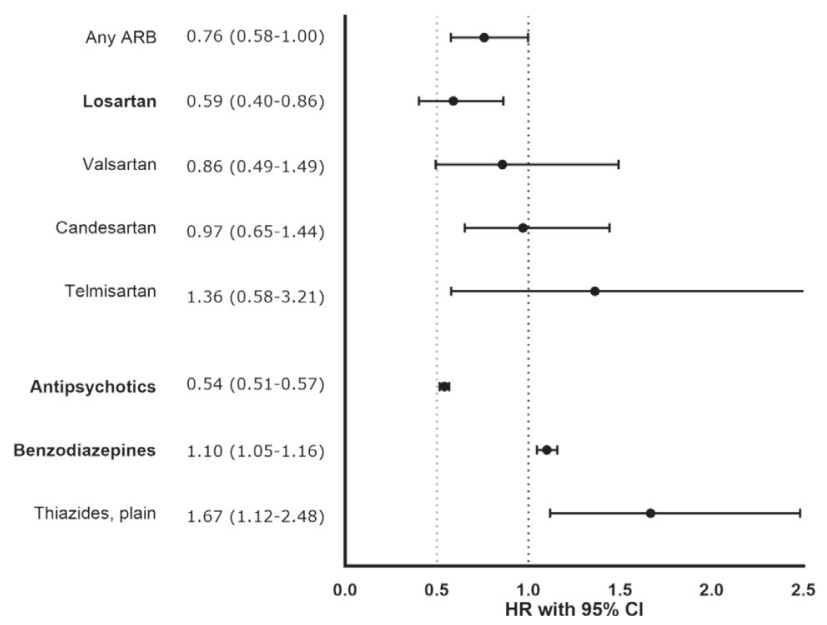

Fig. 3. Risk of psychiatric re-hospitalization during the use of an angiotensin II receptor antagonist (ARB) or thiazide diuretic, antipsychotic, or benzodiazepine vs. no use of the drug. In bold are depicted the agents that are significant after Bonferroni correction. a) Prevalent cohort. p-Values were 0.0001 for any ARB, $<0.0001$ for candesartan, 0.1762 for eprosartan, $<0.0001$ for losartan, $<0.0001$ for valsartan, 0.4345 for telmisartan, 0.9614 for olmesartan, $<0.0001$ for antipsychotics, $<0.0001$ for benzodiazepines, and 0.1439 for thiazides. Cut-off value with Bonferroni correction is $\mathrm{p}<0.0055$. b) Incident cohort. p-Values were 0.0486 for any ARB, 0.0065 for losartan, 0.5880 for valsartan, 0.8800 for candesartan, 0.4795 for telmisartan, $<0.0001$ for antipsychotics, 0.0002 for benzodiazepines, and 0.0121 for thiazides. Cut-off value with Bonferroni correction is $p$ $<0.0071$.

controls were based on previously published results (Tiihonen et al., 2019) it was not possible to further study the effects of master regulators such as losartan or astaxanthin with PCR. If our results relied on one dataset, it would be justified to claim that RNA seq data requires validation by PCR. However, it is very unlikely that replication of similar findings on ADCYAP1, ADAMTS, and CACNA-related pathways from publicly available datasets from two different countries and by two independent research groups could be attributable to methodological issues. We think that this kind of replication using two independent datasets is actually more convincing than validation by PCR in one dataset.

\section{Conclusion}

Our results showed that while glutamatergic alterations in the Finnish dataset and GABAergic alterations in the US dataset were linked with schizophrenia in hiPSC derived neurons corresponding to cells maturing during the second trimester, no consistent signal was observed for dopamine-specific genes in both datasets. This suggests that the inhibitory-excitatory balance between glutamate and GABA may be a primary pathophysiology among patients with Caucasian origin, and dopaminergic deficits emerge later in the cascade when the illness is fully manifested. Therefore, secondary prevention with dopaminergic drugs may be too late for a full recovery, but ADCYAP1/PACAP-deficit alleviators, such as metabotropic glutamate $2 / 3$ agonists, 5-HT7 antagonists, and angiotensin II receptor blockers might be beneficial in the prodromal phase of schizophrenia, and they should be studied in RCTs.

Supplementary data to this article can be found online at https://doi. org/10.1016/j.schres.2021.05.011.

\section{Role of the funding source}

The study was partially funded by the Ministry of Social Affairs and Health, Finland, through the developmental fund for Niuvanniemi Hospital, Business Finland, Sigrid Jusélius Foundation, the University of Helsinki, and the University of Eastern Finland. The funding sources had no role in the design and conduct of the study; collection, management, analysis, and interpretation of the data; preparation, review or approval of the manuscript; and decision to submit the manuscript for publication.

\section{CRediT authorship contribution statement}

JT conceived the study. KT carried out the pathway analyses. ŠL planned and supervised iPSC lines characterizations, differentiation of the neurons, and sample preparation for RNA and protein sequencing. TC, JL, ST, and JS gathered the data on twin pairs. IO and OV performed skin biopsies and rating of symptoms, MK differentiated the neurons and prepared RNA samples for sequencing. ML contributed to the interpretation of the results. AT and HT were in charge of the pharmacoepidemiological analyses. JT wrote the first draft of the manuscript. All authors contributed to the critical revision of the manuscript.

\section{Declaration of competing interest}

The authors have no conflicts of interest to declare.

\section{Acknowledgements}

We thank Laila Kaskela, Eila Korhonen, and Sara Wojciechowski for technical help in generation and characterization of the stem cell lines, and Aija Räsänen for secretarial assistance. No compensation was received outside the usual salary.

\section{References}

Ago, Y., Hiramatsu, N., Ishihama, T., Hazama, K., Hayata-Takano, A., Shibasaki, Y., Shintani, N., Hashimoto, H., Kawasaki, T., Onoe, H., Chaki, S., Nakazato, A., Baba, A., Takuma, K. Matsuda, T., 2013. The selective metabotropic glutamate $2 / 3$ receptor agonist MGS0028 reverses psychomotor abnormalities and recognition memory deficits in mice lacking the pituitary adenylate cyclase-activating polypeptide. Behav. Pharmacol. 24 (1), 74-77. https://doi.org/10.1097/fbp.0b013e32835cf3e5 (PMID: 23268987).

Benicky, J., Sánchez-Lemus, E., Honda, M., Pang, T., Orecna, M., Wang, J., Leng, Y., Chuang, D.-M., Saavedra, J.M., 2011. Angiotensin II AT1 receptor blockade ameliorates brain inflammation. Neuropsychopharmacology. 36 (4), 857-870. https://doi.org/ 10.1038/npp.2010.225.

Berretta, S., 2012. Extracellular matrix abnormalities in schizophrenia. Neuropharmacology. 62 (3), 1584-1597. https://doi.org/10.1016/j.neuropharm.2011.08.010. 
Breen, M.S., Dobbyn, A., Li, Q., Roussos, P., Hoffman, G.E., Stahl, E., Chess, A., Sklar, P., Li, J.B., Devlin, B., Buxbaum, J.D., CommonMind Consortium, 2019. Global landscape and genetic regulation of RNA editing in cortical samples from individuals with schizophrenia. Nat. Neurosci. 22 (9), 1402-1412. https://doi.org/10.1038/s41593-019-0463-7.

Brennand, K.J., Simone, A., Jou, J., Gelboin-Burkhart, C., Tran, N., Sangar, S., Li, Y., Mu, Y., Chen, G., Yu, D., McCarthy, S., Sebat, J., Gage, F.H., 2011. Modelling schizophrenia using human induced pluripotent stem cells. Nature. 473 (7346), 221-225. https:// doi.org/10.1038/nature09915.

Chelini, G., Pantazopoulos, H., Durning, P., Berretta, S., 2018. The tetrapartite synapse: a key concept in the pathophysiology of schizophrenia. Eur. Psychiatry 50, 60-69. https://doi.org/10.1016/j.eurpsy.2018.02.003.

Fan, X., Song, X., Zhao, M., Jarskog, L.F., Natarajan, R., Shukair, N., Freudenreich, O., Henderson, D.C., Goff, D.C., 2017. The effect of adjunctive telmisartan treatment on psychopathology and cognition in patients with schizophrenia. Acta Psychiatr. Scand. 136 (5), 465-472. https://doi.org/10.1111/acps.12799.

Gandal, M.J., Zhang, P., Hadjimichael, E., Walker, R.L., Chen, C., Liu, S., Won, H., van Bakel, H., Varghese, M., Wang, Y., Shieh, A.W., Haney, J., Parhami, S., Belmont, J., Kim, M., Moran Losada, P., Khan, Z., Mleczko, J., Xia, Y., Dai, R., Wang, D., Yang, Y.T., Xu, M., Fish, K., Hof, P.R., Warrell, J., Fitzgerald, D., White, K., Jaffe, A.E., PsychENCODE Consortium, Peters, M.A., Gerstein, M., Liu, C., Iakoucheva, L.M., Pinto, D., Geschwind, D.H., 2018. Transcriptome-wide isoform-level dysregulation in ASD, schizophrenia, and bipolar disorder. Science 362 (6420), eaat8127. https://doi.org/ 10.1126/science.aat8127.

Girdhar, K., Hoffman, G.E., Jiang, Y., Brown, L., Kundakovic, M., Hauberg, M.E., Francoeur, N.J., Wang, Y.C., Shah, H., Kavanagh, D.H., Zharovsky, E., Jacobov, R., Wiseman, J.R., Park, R., Johnson, J.S., Kassim, B.S., Sloofman, L., Mattei, E., Weng, Z., Sieberts, S.K., Peters, M.A., Harris, B.T., Lipska, B.K., Sklar, P., Roussos, P., Akbarian, S., 2018. Cellspecific histone modification maps in the human frontal lobe link schizophrenia risk to the neuronal epigenome. Nat. Neurosci. 21 (8), 1126-1136. https://doi.org/ 10.1038/s41593-018-0187-0.

Hayata-Takano, A., Kamo, T., Kijima, H., Seiriki, K., Ogata, K., Ago, Y., Nakazawa, T., Shintani, Y., Higashino, K., Nagayasu, K., Shintani, N., Kasai, A., Waschek, J.A., Hashimoto, H., 2019. Pituitary adenylate cyclase-activating polypeptide modulates dendritic spine maturation and morphogenesis via microRNA-132 upregulation. J. Neurosci. 39 (22), 4208-4220. https://doi.org/10.1523/JNEUROSCI.2468-18.2019.

Hirota, T., Kishi, T., 2013. Adenosine hypothesis in schizophrenia and bipolar disorder: a systematic review and meta-analysis of randomized controlled trial of adjuvant purinergic modulators. Schizophr. Res. 149 (1-3), 88-95. https://doi.org/10.1016/j. schres.2013.06.038.

Hoffman, G.E., Hartley, B.J., Flaherty, E., Ladran, I., Gochman, P., Ruderfer, D.M., Stahl, E.A., Rapoport, J., Sklar, P., Brennand, K.J., 2017. Transcriptional signatures of schizophrenia in hiPSC-derived NPCs and neurons are concordant with post-mortem adult brains. Nat. Commun. 8 (1), 2225. https://doi.org/10.1038/s41467-017-02330-5.

Hong, S., JianCheng, H., JiaWen, W., ShuQin, Z., GuiLian, Z., HaiQin, W., Ru, Z., Zhen, G., HongWei, R., 2019. Losartan inhibits development of spontaneous recurrent seizures by preventing astrocyte activation and attenuating blood-brain barrier permeability following pilocarpine-induced status epilepticus. Brain Res. Bull. 149, 251-259. https://doi.org/10.1016/j.brainresbull.2019.05.002.

Kim, S.Y., Senatorov Jr., V.V., Morrissey, C.S., Lippmann, K., Vazquez, O., Milikovsky, D.Z., Gu, F., Parada, I., Prince, D.A., Becker, A.J., Heinemann, U., Friedman, A., Kaufer, D., 2017. TGF $\beta$ signaling is associated with changes in inflammatory gene expression and perineuronal net degradation around inhibitory neurons following various neurological insults. Sci. Rep. 7, 7711. https://doi.org/10.1038/s41598-017-07394-3.

Krämer, A., Green, J., Pollard Jr., J., Tugendreich, S., 2014. Causal analysis approaches in Ingenuity Pathway Analysis. Bioinformatics. 30 (4), 523-530. https://doi.org/10.1093/ bioinformatics/btt703.

Lutfy, K., Shankar, G., 2019. Emerging evidence for the role of pituitary adenylate cyclaseactivating peptide in neuropsychiatric disorders. Prog. Mol. Biol. Transl. Sci. 167, 143-157. https://doi.org/10.1016/bs.pmbts.2019.06.009.

Marvar, P.J., Goodman, J., Fuchs, S., Choi, D.C., Banerjee, S., Ressler, K.J., 2014. Angiotensin type 1 receptor inhibition enhances the extinction of fear memory. Biol. Psychiatry 75 (11), 864-872. https://doi.org/10.1016/j.biopsych.2013.08.024.

McCutcheon, R.A., Krystal, J.H., Howes, O.D., 2020. Dopamine and glutamate in schizophrenia: biology, symptoms and treatment. World Psychiatry 19 (1), 15-33. https://doi.org/10.1002/wps.20693.

Narla, S.T., Lee, Y.-W., Benson, C.A., Sarder, P., Brennand, K.J., Stachowiak, E.K., Stachowiak, M.K., 2017. Common developmental genome deprogramming in schizophrenia - role of Integrative Nuclear FGFR1 Signaling (INFS). Schizophr. Res. 185, 17-32. https://doi org/10.1016/j.schres.2016.12.012.

Oh, S.J., Fan, X., 2019. The possible role of the angiotensin system in the pathophysiology of schizophrenia: implications for pharmacotherapy. CNS Drugs 33 (6), 539-547. https://doi.org/10.1007/s40263-019-00632-4.

Pardiñas, A.F., Holmans, P., Pocklington, A.J., Escott-Price, V., Ripke, S., Carrera, N., Legge, S.E., Bishop, S., Cameron, D., Hamshere, M.L., Han, J., Hubbard, L., Lynham, A. Mantripragada, K., Rees, E., MacCabe, J.H., McCarroll, S.A., Baune, B.T., Breen, G., Byrne, E.M., Dannlowski, U., Eley, T.C., Hayward, C., Martin, N.G., McIntosh, A.M., Plomin, R., Porteous, D.J., Wray, N.R., Caballero, A., Geschwind, D.H., Huckins, L.M., Ruderfer, D.M., Santiago, E., Sklar, P., Stahl, E.A., Won, H., Agerbo, E., Als, T.D., Andreassen, O.A., Bækvad-Hansen, M., Mortensen, P.B., Pedersen, C.B., Børglum, A.D., Bybjerg-Grauholm, J., Djurovic, S., Durmishi, N., Pedersen, M.G., Golimbet, V., Grove, J., Hougaard, D.M., Mattheisen, M., Molden, E., Mors, O., Nordentoft, M., Pejovic-Milovancevic, M., Sigurdsson, E., Silagadze, T., Hansen, C.S., Stefansson, K. Stefansson, H., Steinberg, S., Tosato, S., Werge, T., GERAD1 Consortium, CRESTAR Consortium, Collier, D.A., Rujescu, D., Kirov, G., Owen, M.J., O’Donovan, M.C., Walters, J.T.R., 2018. Common schizophrenia alleles are enriched in mutationintolerant genes and in regions under strong background selection. Nat. Genet. 50 (3), 381-389. https://doi.org/10.1038/s41588-018-0059-2.

Schizophrenia Working Group of the Psychiatric Genomics Consortium, 2014. Biological insights from 108 schizophrenia-associated genetic loci. Nature. 511 (7510), 421-427. https://doi.org/10.1038/nature13595.

Sekar, A., Bialas, A.R., de Rivera, H., Davis, A., Hammond, T.R., Kamitaki, N., Tooley, K., Presumey, J., Baum, M., Van Doren, V., Genovese, G., Rose, S.A., Handsaker, R.E., Schizophrenia Working Group of the Psychiatric Genomics Consortium, Daly, M.J., Carroll, M.C., Stevens, B., McCarroll, S.A., 2016. Schizophrenia risk from complex variation of complement component 4. Nature. 530 (7589), 177-183. https://doi.org/ 10.1038/nature16549.

Sellgren, C.M., Gracias, J., Watmuff, B., Biag, J.D., Thanos, J.M., Whittredge, P.B., Fu, T., Worringer, K., Brown, H.E., Wang, J., Kaykas, A., Karmacharya, R., Goold, C.P., Sheridan, S.D., Perlis, R.H., 2019. Increased synapse elimination by microglia in schizophrenia patient-derived models of synaptic pruning. Nat. Neurosci. 22 (3), 374-385. https://doi.org/10.1038/s41593-018-0334-7.

Su, J., Cole, J., Fox, M.A., 2017. Loss of interneuron-derived collagen XIX leads to a reduction in perineuronal nets in the mammalian telencephalon. ASN Neuro 9 (1), 1759091416689020. https://doi.org/10.1177/1759091416689020.

Swissa, E., Serlin, Y., Vazana, U., Prager, O., Friedman, A., 2019. Blood-brain barrier dysfunction in status epileptics: mechanisms and role in epileptogenesis. Epilepsy Behav. 101 (Pt B), 106285. https://doi.org/10.1016/j.yebeh.2019.04.038.

Tajiri, M., Hayata-Takano, A., Seiriki, K., Ogata, K., Hazama, K., Shintani, N., Baba, A., Hashimoto, H., 2012. Serotonin 5-HT(7) receptor blockade reverses behavioral abnormalities in PACAP-deficient mice and receptor activation promotes neurite extension in primary embryonic hippocampal neurons: therapeutic implications for psychiatric disorders. J. Mol. Neurosci. 48 (3), 473-481. https://doi.org/10.1007/ s12031-012-9861-y.

Tiihonen, J., Koskuvi, M., Storvik, M., Hyötyläinen, I., Gao, Y., Puttonen, K.A., Giniatullina, R., Poguzhelskaya, E., Ojansuu, I., Vaurio, O., Cannon, T.D., Lönnqvist, J., Therman, S., Suvisaari, J., Kaprio, J., Cheng, L., Hill, A.F., Lähteenvuo, M., Tohka, J., Giniatullin, R., Lehtonen, Š., Koistinaho, J., 2019. Sex-specific transcriptional and proteomic signatures in schizophrenia. Nat. Commun. 10 (1), 3933. https://doi.org/10.1038/s41467019-11797-3.

Villapol, S., Saavedra, J.M., 2015. Neuroprotective effects of angiotensin receptor blockers. Am. J. Hypertens. 28 (3), 289-299. https://doi.org/10.1093/ajh/hpu197.

Wen, T.H., Binder, D.K., Ethell, I.M., Razak, K.A., 2018. The perineuronal 'safety' net? Perineuronal net abnormalities in neurological disorders. Front. Mol. Neurosci. 11, 270. https://doi.org/10.3389/fnmol.2018.00270.

Xu, C., Yang, X., Sun, L., Yang, T., Cai, C., Wang, P., Jiang, J., Qing, Y., Hu, X., Wang, D., Wang, P., Cui, G., Zhang, J., Li, Y., Ji, F., Liu, C., Wan, C., 2019. An investigation of calciumindependent phospholipase A2 (iPLA2) and cytosolic phospholipase A2 (CPLA2) in schizophrenia. Psychiatry Res. 273, 782-787. https://doi.org/10.1016/j. psychres.2019.01.095.

Yang, A.C., Tsai, S.J., 2017. New targets for schizophrenia treatment beyond the dopamine hypothesis. Int. J. Mol. Sci. 18 (8), 1689. https://doi.org/10.3390/ijms18081689.

Zhu, X.C., Yu, J.T., Jiang, T., Wang, P., Cao, L., Tan, L., 2015. CR1 in Alzheimer's disease. Mol Neurobiol. 51 (2), 753-765. https://doi.org/10.1007/s12035-014-8723-8. 